\title{
Obesity and Functional Gastrointestinal Diseases in Children
}

(Int J Obes [Lond] Published Online First: 2 May 2014. doi: 10.1038/ijo.2014.67)

\section{Shaman Rajindrajith, ${ }^{1 *}$ Niranga M Devanarayana ${ }^{2}$ and Marc A Benninga ${ }^{3}$}

Departments of ${ }^{1}$ Pediatrics and ${ }^{2}$ Physiology, Faculty of Medicine, University of Kelaniya, Ragama, Sri Lanka; and ${ }^{3}$ Department of Pediatric Gastroenterology and Nutrition, Emma Children's Hospital, Academic Medical Center, Amsterdam, The Netherlands

\section{Summary}

Childhood obesity is spreading across the world very fast. Although initial data showed it as a problem of affluence, both developed and developing countries are almost equally affected with the epidemic. It is well known that obesity predisposes both children and adults to several serious disease conditions that can be life threatening. However, in addition to that, data are emerging that obesity predisposes children to develop an array of functional gastrointestinal diseases (FGIDs).

Recently, Phatak and Pashankar ${ }^{1}$ have published an eye opening article to establish the relationship between obesity in children and FGIDs. They have recruited 450 children from 3 paediatric and adolescent clinics in Yale, USA. Children and their parents were interviewed using the standard Rome III questionnaire for children/adolescents. Medical records of these children were comprehensively reviewed to obtain information regarding data on demography and growth indices. Their data show an alarmingly high prevalence of obesity/overweight (42\%). Functional abdominal pain syndrome (FAPS) (OR, 2.1; 95\% CI, 1.21-3.64; $P=0.007)$, functional constipation (FC) (OR, $1.83 ; 95 \% \mathrm{CI}, 1.12-2.98 ; P=0.01)$ and irritable bowel syndrome (IBS) (OR, 2.59; 95\% CI, 1.40-4.79; $P=0.003$ ) were noted to be significantly more prevalent in the obese/overweight children. Of the obese/overweight children, $47 \%$ had at least one functional gastrointestinal disorder compared with $27 \%$ of the normal weight children $(P<0.001)$.

\section{Comment}

Childhood obesity is a global pandemic. Prevalence data shows that it is spreading across all continents and crossing the boundaries easily than imagined in the past. ${ }^{2}$ It looks like the whole world has become an "obesogenic environment" irrespective of the socio-economic status. Developed countries have single burden of obesity whereas the developing world has the dual burden of both obesity and malnutrition. ${ }^{2}$ The health related

Received: May 30, 2014 Revised: None Accepted: June 2, 2014

(c) This is an Open Access article distributed under the terms of the Creative Commons Attribution Non-Commercial License (http://creativecommons. org/licenses/by-nc/3.0) which permits unrestricted non-commercial use, distribution, and reproduction in any medium, provided the original work is properly cited.

*Correspondence: Shaman Rajindrajith, MD

Department of Pediatrics, Faculty of Medicine, University of Kelaniya, Thalagolla Road, Ragama 11010, Sri Lanka

Tel: +94-112-958039, Fax: +94-112-958337, E-mail: shamanrajindrajith4@gmail.com

Financial support: None.

Conflicts of interest: None.

Author contributions: Shaman Rajindrajith and Niranga M Devanarayana contributed equally to plan and writing the commentary; Marc A Benninga contributed by critically analyzing the manuscript and providing valuable intellectual input.

ORCID: Shaman Rajindrajith, http://orcid.org/0000-0003-1379-5052; Niranga M Devanarayana, http://orcid.org/0000-0002-2988-110X; Marc A Benninga, http://orcid.org/0000-0001-9406-9188. 
repercussions of this global pandemic are alarming. Obese/ overweight children are predisposed to develop hypertension, diabetes, liver diseases ranging from simple steatosis to cirrhosis, and cancer. ${ }^{3}$

In addition to above mentioned life threatening problems, several investigators have noted FGIDs are significantly more common in children with obesity. In a prospective study of children with FGIDs, Bonilla et $\mathrm{al}^{4}$ found obese patients complain more pain intensity, higher pain frequency, more school absenteeism and more disruption of daily activities. Another study assessed children referred to a paediatric gastroenterology clinic and compared them with local population. In that study, IBS, FC and encopresis were more commonly prevalent among obese children. ${ }^{5}$ The main limitation of this study was that the study population was drawn from a specialized gastroenterology clinic. Evaluating 80 obese children, Fishman et $\mathrm{al}^{6}$ found that faecal soiling (incontinence) was significantly higher in obese children. One important drawback of this study was it does not have a control group. Van der Baan-Slootweg et $\mathrm{al}^{7}$ reported a prevalence of $21 \%$ and $1 \%$, respectively of $\mathrm{FC}$ and functional non-retentive faecal incontinence, in 91 children, 15 years (8-18 years) treated for morbid obesity (corrected body mass index $>35$ or 30 $\mathrm{kg} / \mathrm{m}^{2}$ ) in a specialized obesity clinic in The Netherlands.

In this backdrop, Phatak and Pashnker ${ }^{1}$ have conducted a well designed study to further highlight the importance of the association between obesity and FGIDs. The study was conducted in a general paediatric clinic without a bias towards either obesity or to FGIDs. They also used the standardized Rome III questionnaire to ascertain the Rome III criteria for the diagnosis. The study also has an appropriate control group from the same population. With these strengths, they have noted higher prevalences of IBS, FAPS and FC in obese children. They have also found that obese children have a higher predilection to develop FGIDs than children with normal weight.

The mechanisms of obese children to develop FGIDs more than controls are not entirely evident. Physiological studies of gastrointestinal tract of obese children are limited. The study conducted in The Netherlands has found children with morbid obesity have significantly delayed colonic transit, possibly predisposing them to develop FC. However, the high prevalence of functional defecation disorders in these morbid obese children could not be explained by differences in the diet, especially in fibre or fat intake, both influencing gut transit time. ${ }^{7}$ In addition, another study noted children with obesity showed poor gastric accommodation to satiety drink test at least partly explaining possible pathophysiological mechanism for them to develop pain predominant FGIDs such as FAPS and IBS. ${ }^{8}$ Clearly more research is needed to understand and explain the phenomenon of developing FGIDs in obese children.

Recent Asian data have shown higher prevalence of FGIDs. Prevalence of IBS ranges from $4.2 \%$ in Iran to $26 \%$ in Korean girls. ${ }^{9,10}$ Similarly, FC was found to be ranging from $15 \%$ among Sri Lankan school children to $30 \%$ among young children attending kindergarten in Hong Kong. ${ }^{11,12}$ Furthermore, other FGIDs such as functional abdominal pain, and abdominal migraine are also common among Asian children and adolescents. ${ }^{13}$

It is also notable that Asia is also facing the rising tide of obesity. Data from China have noted 30-49\% of their children are obese or overweight. ${ }^{14}$ Furthermore, developing countries such as Bangladesh and Sri Lanka also show a significant proportion of their children $(3.5 \%)$ are obese or overweight. ${ }^{15,16}$ In this light the findings of Phatak and Pashankar ${ }^{1}$ gives us an alarm signal. In addition to well-known risk factors already existed, young generation in Asia is now getting exposed to new predisposing factors (obesity and overweight) leaving them more vulnerable to develop FGIDs.

FGIDs although not directly related to mortality are associated with significant morbidity. Several studies have confirmed children with pain predominant FGIDs are having poor health related quality of life. ${ }^{17,18}$ We have recently shown that children with FC have poor health-related quality of life (HRQoL) and suffer from number of somatic symptoms which contribute to spiral down their HRQoL further. ${ }^{19}$ Sagawa et $\mathrm{al}^{20}$ noted children with IBS have poor school performances indicating long term repercussions of FGDs in children.

Taking these data into account, paediatricians, gastroenterologists and health authorities in Asia should join hands to examine the data on obesity and FGIDs. Addressing these glaring facts is utmost important to minimize the dual burden of both obesity and FGIDs by implementing appropriate measures to curtail the sweeping epidemic before it grows up to uncontrollable proportions.

\section{References}

1. Phatak UP, Pashankar DS. Prevalence of functional gastrointestinal disorders in obese and overweight children. Int J Obes (Lond) Published Online First: 2 May 2014. doi: 10.1038/ijo.2014.67.

2. Swinburn BA, Sacks G, Hall G, et al. The global obesity pandemic: shaped by global drivers and local environments. Lancet 2011; 27:804-814. 
3. Kanasaki K, Kova D. Biology of obesity: lessons from Animal models of obesity. J Biomed Biotechnol 2011;2011:197636.

4. Bonilla S, Wang D, Saps M. Obesity predicts persistence of pain in children with functional gastrointestinal disorders. Int $\mathrm{J}$ Obes (Lond) 2011;35:517-521.

5. Teitelbaum JE, Sinha P, Micale M, Yeung S, Jaeger J. Obesity is related to multiple functional abdominal disease. J Pediatr 2009;154: 444-446.

6. Fishman L, Lenders C, Fortunato C, Noonan C, Nurko S. Increased prevalence of constipation and fecal soiling in a population of obese children. J Pediatr 2004;145:253-254.

7. vdBaan-Slootweg OH, Liem O, Bekkali N, et al. Constipation and colonic transit times in children with morbid obesity. J Pediatr Gastroenterol Nutr 2011;52:442-445.

8. Hoffman I, Tack J. Assessment of gastric motor function in childhood functional dyspepsia and obesity. Neurogastroenterol Motil 2012;24:108-112, e81.

9. Sohrabi S, Nouraie M, Khademi H, Baghizadeh S, NasseriMoghaddam S, Malekzadeh R. Epidemiology of uninvestigated gastrointestinal symptoms in adolescents: a population-based study applying the Rome III questionnaire. J Pediatr Gastroenterol Nutr 2010;51:41-45.

10. Son YJ, Jun EY, Park JH. Prevalence and risk factors of irritable bowel syndrome in Korean adolescent girls: a school-based study. Int J Nurs Stud 2009;46:76-84.

11. Rajindrajith S, Devanarayana NM, Adhikari C, Pannala W, Benninga MA. Constipation in children: an epidemiological study in Sri Lanka using Rome III criteria. Arch Dis Child 2012;97:43-45.

12. Ip KS, Lee WT, Chan JS, Young BW. A community-based study of the prevalence of constipation in young children and the role of dietary fiber. Hong Kong Med J 2005;11:431-436.

13. Devanarayana NM, Mettananda S, Liyanarachchi C, et al. Abdominal pain predominant functional gastrointestinal diseases in children and adolescents: symptomatology and association with stress. J Paediatr Gastroenterol Nutr 2011;53:659-665.

14. Jiang XX, Hardy LL, Baur LA, Ding D, Wang L, Shi HJ. High prevalence of overweight and obesity among inner city Chinese children in Shanghai, 2011. Ann Hum Biol Published Online First: 15 May 2014. doi:10.3109/03014460.2014.910270.

15. Bulbul T, Hoque M. Prevalence of childhood obesity and overweight in Bangladesh: findings from a countrywide epidemiological survey. BMC Pediatr 2014;14:86.

16. Wickramasinghe VP, Arambepola C, Bandara P, et al. Distribution of obesity-related metabolic markers among 5-15 years old children from an urban area of Sri Lanka. Ann Hum Biol 2013;40:168-174.

17. Varni JW, Lane MM, Burwinkle TM, et al. Health-related quality of life in pediatric patients with irritable bowel syndrome: a comparative analysis. J Dev Behav Pediatr 2006;27:451-458.

18. Youssef NN, Murphy TG, Langseder AL, Rosh JR. Quality of life for children with functional abdominal pain: a comparison study of patients' and parents' perception. Pediatrics 2006;117:54-59.

19. Rajindrajith S, Devanarayana NM, Weerasooriya L, Hathagoda W, Benninga MA. Quality of life and somatic symptoms in children with constipation: a school-based study. J Pediatr 2013;163:1069-1072, e1.

20. Sagawa T, Okamura S, Kakizaki S, Zhang Y, Morita K, Mori M.Functional gastrointestinal disorders in adolescents and quality of school life. J Gastroenterol Hepatol 2013;28:285-290. 